\title{
PHOTOGRAMMETRIC ARCHAEOLOGICAL SURVEY WITH UAV
}

\author{
A. Mouget ${ }^{a}$, G. Lucet $^{b}$ \\ ${ }^{\text {a }}$ ENSG, National School of Geomatics, 77420 Champs-sur-Marne, France - anna.mouget@ensg.eu \\ ${ }^{\mathrm{b}}$ Institute of Aesthetic Research, Universidad Nacional Autónoma de México, Mexico - genevieve.lucet@gmail.com
}

Commission V

KEY WORDS: UAV (Unmanned Aerial Vehicles), photogrammetry, MicMac, orthophoto, 3D model, archaeological site, survey

\begin{abstract}
:
This document describes a way to obtain various photogrammetric products from aerial photograph using a drone. The aim of the project was to develop a methodology to obtain information for the study of the architecture of pre-Columbian archaeological sites in Mexico combining the manoeuvrability and low cost of a drone with the accuracy of the results of the open source photogrammetric MicMac software. It presents the UAV and the camera used, explains how to manipulate it to carry out stereoscopic photographs, the flight and camera parameters chosen, the treatments performed to obtain orthophotos and 3D models with a centimetric resolution, and finally outlines the quality of the results.
\end{abstract}

\section{INTRODUCTION}

The measurement system of the pre-Columbian builders is still an enigma to archaeologists today. A comprehensive study in this field should be based on accurate measurements of dimensions and alignments of each structure. Maps of Mexican archaeological sites available in the literature have an insufficient precision to perform such research; consequently, for the study of each archaeological site, a precise survey must be done.

Several solutions are available for archaeological survey: a topographical survey can produce accurate measurements that can be processed with software to obtain maps and 3D models. Nevertheless, with a total station, it is impossible to register each stone and deformation of the ruins. Thus the representation is a synthesis and an interpretation of the information. A second solution would be using a laser scanner. Unfortunately, archaeological sites can be quite widespread and have many monuments, so the number of stations to be performed and the number of point cloud to be processed would demand too much post processing resources. A third solution is to use a drone to acquire aerial photographs of sites, and process them to create orthophotos and 3D point clouds.

It is this third option that has been adopted here, and will be described below. It was applied to the survey of the archaeological site of Cempoala (Mexico).

This project was made during a student internship and is part of a work about pre-Columbian architecture carried out by a research team from the Institute of Aesthetic Research (IIE) of the University of Mexico (UNAM).

The objectives of this project were multiple. First, the development of a working method to achieve stereoscopic photographs with the Institute's drone. Then, to realize a photogrammetric aerial photograph of an archaeological site with the drone. Finally, to carry out the treatments required to obtain orthophotos and a 3D model of the site. A working method was developed, as well as a calculation method for the various parameters of the flight, and quality control was conducted to determine the precision of the results.

\section{EQUIPMENT}

\subsection{UAV}

Drones can be considered dangerous because they do not have a transmitter signalling their position to other aircrafts, and in some countries, they may be used by amateurs who might not have received previous training. However, they have many advantages, such as their affordability and manoeuvrability.

When the first drones appeared in the 70s, they were either wind sensitive or subject to significant vibration. Since 2000, drones have become more adapted to aerial photography, and the first studies on the quality of the results were performed (Eisenbeiß, 2013).

Nowadays, drones commonly have automatic drivers and automatic image acquisition. A predefined point to rejoin if the connection is lost can even be registered in the memory of the UAV. Models with rotors are appreciated for their vertical takeoff and landing on a small areas, and their workability. As for aircraft models, they are preferred for their greater autonomy.

Drones are now used in many fields: military, agriculture, tectonic, geology, atmospheric, archaeology, extreme sport...

The drone in possession of the working group is a hexacopter Spreading Wings S800 (Figure 1), equipped with the on-board computer Wookong-M associated with IMU (Inertial Measurement Unit) and GNSS receiver. Both are developed by the Chinese company DJI. The drone is controlled by a remote Futuba 7C. 


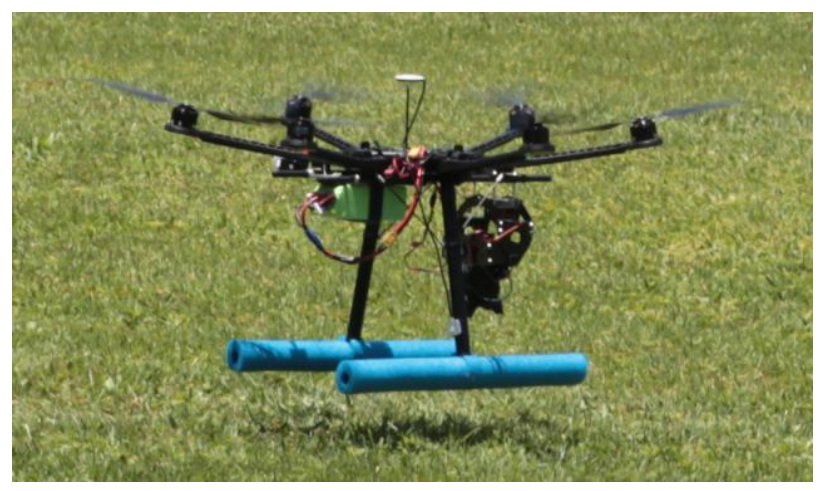

Figure 1. Spreading Wings S800 hexacopter with the Sony Nex7 camera

The drone has a maximum horizontal speed of $25 \mathrm{~m} / \mathrm{s}$ and a vertical speed limit of $5 \mathrm{~m} / \mathrm{s}$. The maximum recommended distance between the remote control and the drone is $500 \mathrm{~m}$ in a city and up to $1 \mathrm{~km}$ in open field. The drone is operated using pairs of batteries, which are recharged with devices able to deliver a 30 amps electric current. The group has three sets of batteries, each allowing about fifteen minutes of flight.

The UAV can fly using the remote control in three different modes:

- The GPS mode, the most advanced one, in which the drone uses information from the GPS and the IMU to better respond to the instructions of the driver-handled remote control. This mode also helps to maintain a stable position and attitude when the drone receives no movement command from the ground.

- The ATTI mode, which does not use the position information from the GPS, but only those of the inertial unit. In this mode, the drone does not maintain its position, but only its attitude (orthogonal to the ground). Therefore, the drone presents inertia at the end of his movements, even though the remote control indicates a stationary position. In a windy environment, it would be carried adrift.

- A fully manual mode, in which the movements of the drone are only governed by indications from the remote control. This method is difficult to use and not recommended because without GPS and IMU data, the drone preserves neither a stable position, nor a stable attitude.

\subsection{Ground Station software}

The drone is sold with the software Ground Station which provides a variety of aids for the manipulation of the drone.

This software displays on Google Earth the trajectory and the position taken by the drone.

The green line corresponds to the drone trajectory. Unfortunately, its extraction is not allowed. The red arrow represents the drone, with the tip symbolizing its front. The height of the drone over its takeoff point is indicated in blue. (Figure 2)

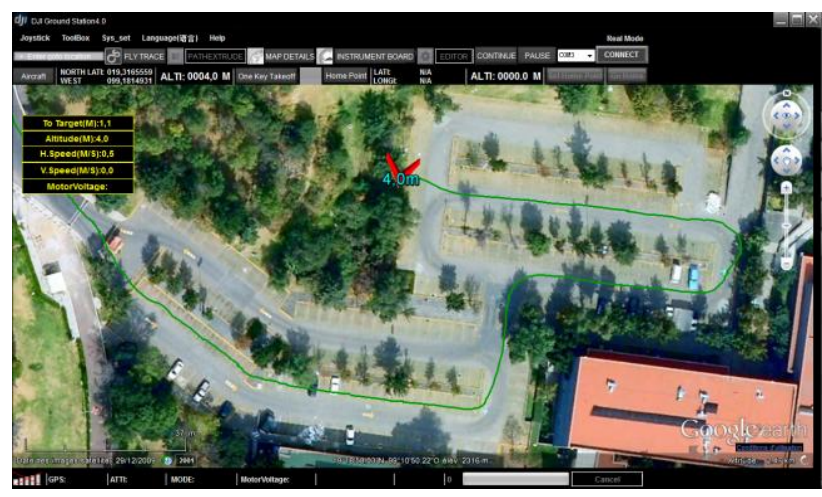

Figure 2. Ground Station software interface

A flight can be planned with the software. Indeed, a theoretical trajectory can be defined before the flight, and then, once on the field, the UAV can follow it using its GPS (Figure 3).

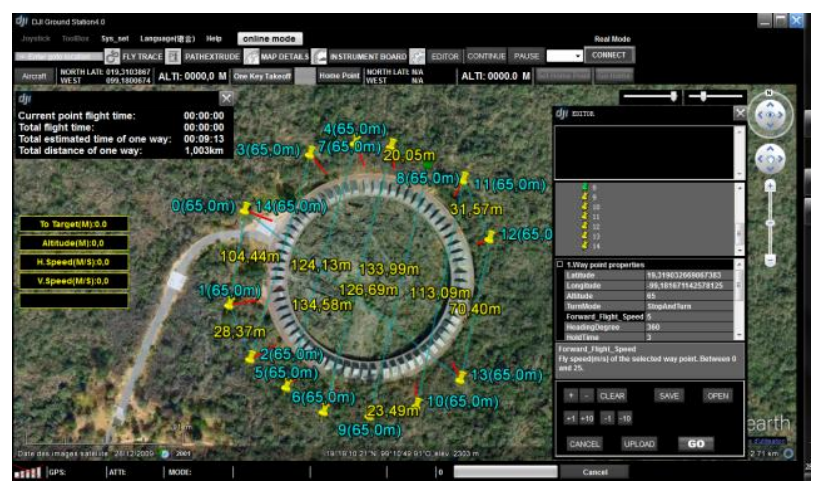

Figure 3. Ground Station's flight plan editor

The planned trajectory is displayed in blue. Yellow pins correspond to the vertices of the path. The red lines project the position of the UAV on the ground. The vertices' order numbers are written in blue with their height, the distances between two consecutive vertices of the path are in yellow. Furthermore, the distance and the duration of the whole flight are calculated and indicated by Ground Station software.

Thanks to this autopilot, equidistant flight axis can be planned, and this ensures constant speed and altitude of the device. Consequently, during the flight, the remote control lets the control of the drone to the software, even if the driver can regain it at any time.

At the time we realized this project (August 2013), this software integrated different functional possibilities depending on the purchase price. The least expensive version allowed only indicating a return point while the more expensive version was conceived for photogrammetric use and allowed to design a flight with 50 vertices. The new version of the software includes the 50 points, nevertheless, at that time we had to work with the two points version.

\subsection{Camera and its automatic shutter release}

The camera used is a Sony Nex-7. It has a 24 Megapixel matrix with $28 \mathrm{~mm}$ diagonal and it is equipped with a zoom lens ranging from 18 to $55 \mathrm{~mm}$.

The camera is attached to the drone with a MRT Crane 2 Camera Gimbal Axis 2 mount, which allows countering the 
inclination of the device due to its movement using the guidance provided by the inertial unit, and thus, to always maintain the camera orthogonal to the ground.

The capture of the pictures is controlled by the gentLEDTRIGGER-triggerPLUS infrared trigger. It can, in theory, have a minimum rate of 2 seconds shooting, but it turned out that, in practice, it does not go below 2.3 seconds.

\subsection{Georeferencing accuracy}

We saw previously that flight planning associated with autopilot flight mode greatly simplifies the flight. However, it is interesting to measure the accuracy of the GNSS positioning before letting him the control.

Two factors have an influence on the positioning of the drone: the georeferencing accuracy of Google Earth images, on which the trajectory of the drone is defined, and the accuracy of the GPS (helped by the IMU).

Concerning the GPS-IMU couple, the manufacturer indicates an in-flight accuracy of $0.5 \mathrm{~m}$ vertically and $1 \mathrm{~m}$ horizontally.

To have an idea of the accuracy of Google Earth images georeferencing, a comparison of coordinates given by the GPS of the drone and by Google Earth on the same points were made. After coordinate transformation in the same system, deviations exceeding GPS accuracy given by the manufacturer are calculated. This difference can be associated partially to the georeferencing of Google Earth images. The maximum obtained is $6.5 \mathrm{~m}$ and it does not exclude that in other places, the difference could be larger.

However, these coordinates were recorded with a stationary GPS, eliminating the correction from the IMU. Indeed, the IMU measures angular accelerations and velocities when the UAV is moving. So, positioning is improved when the drone is moving, although differences between the real position of the drone and its location indicated on the Google Earth API persist: this is the case in figure 2, where the trajectory was obtained with the drone lying inside a car that was obviously not rolled over parking spaces.

Thus, during flight planning, the distance between the axis of flight must be chosen taking into account the few meters imprecision, in order to prevent a possible gap of the real axis of flight and therefore of the footprint of the photographs.

\section{AERIAL PHOTOGRAPH PARAMETERS}

\subsection{Parameters of the camera}

Obtaining photogrammetric products with the MicMac software requires identical camera settings throughout the shooting. The optical parameters must be set prior to each flight, according to the brightness (CIPA, 1988). To have good quality pictures, the ISO must not exceed 800. After some tests to compare different settings for opening and exposure time, we concluded that it was preferable to use an exposure time of 1/2000 or more, and adapt the opening with the brightness. These three parameters will thus remain fixed throughout the shooting. The camera is at least several dozens of meters from the ground (ground distance), so there will be no problem with depth of field, even if the opening is small.

The drawback in the use of this camera is its focus ring which is endless and without graduations, making it uneasy to set the focus to infinity, and to fix it.

\subsection{Flight parameters}

Flight parameters include: flying height above the highest point of the site, flight speed, focal length, shooting rate. They will directly define the image resolution, the footprint of a photo and the overlap between photos (Ferrières (de), 2004). The stereoscopic base is the distance between two summits $S_{i}$, which is also the difference between the footprint and the overlap (Figure 4).

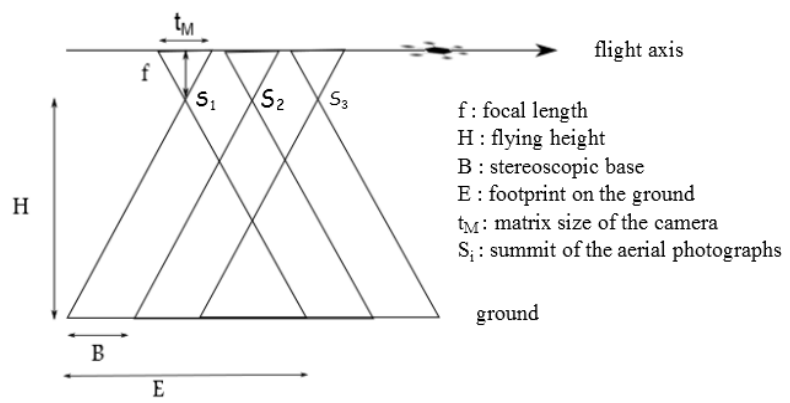

Figure 4. Representation of aerial photos parameters

It was decided that the resolution of the photos should be close to one centimeter. It is obtained as a function of the pixel size of the camera, of the focal length and the flying height. The resolution of the ground is given by the following formula:

$$
R=(H+h) * \frac{t p x}{f}
$$

$$
\begin{array}{ll}
\text { where } & \mathrm{R}=\text { resolution } \\
\mathrm{H}=\text { flying height } \\
\mathrm{h}=\text { height of the taller monument } \\
\mathrm{t}_{\mathrm{px}}=\text { pixel size } \\
\mathrm{f}=\text { focal length }
\end{array}
$$

Recoveries between images needed for the proper functioning of the MicMac software are $60 \%$ along the flight axis and $20 \%$ between bands. However, to guard both against a slower rate of the infrared trigger, and against the vagueness of Google Earth georeferencing, it is better to fix the parameters of the aerial involving $65 \%$ in forward overlap and $60 \%$ between strips for side overlap (Figure 5).

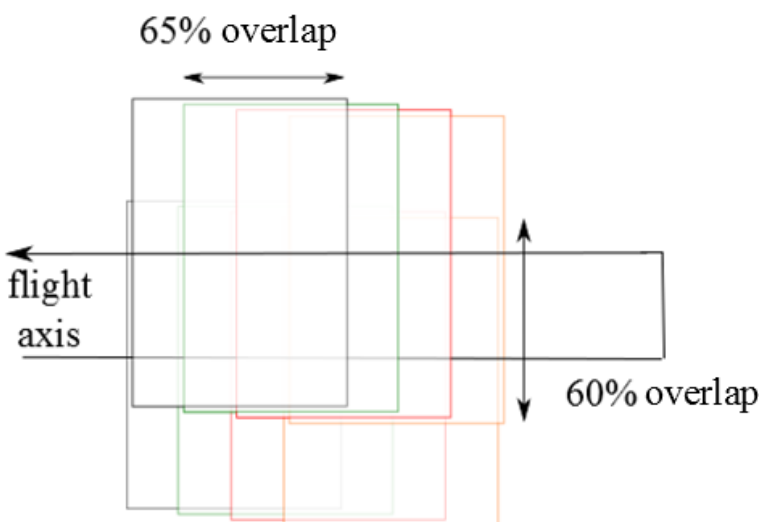

Figure 5. Representation of overlap from above 
The footprint of the photos must be calculated with a flying height starting at the highest point of the site in order for buildings not to get out of the aerial photograph, and present enough overlap at the top (Figure 6).

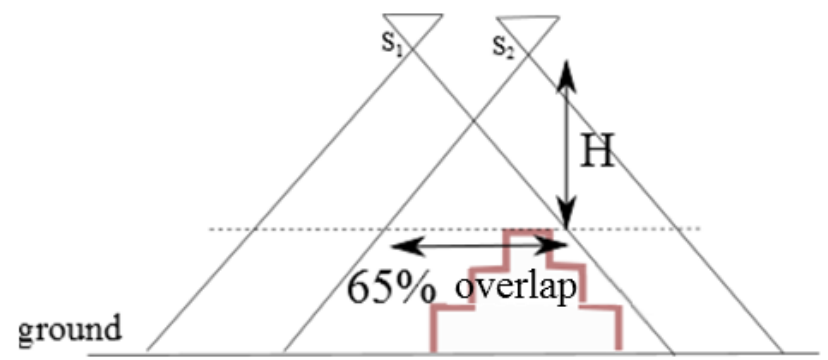

Figure 6. Flight height and overlap above relief

The choice of the flight parameters is then a compromise between flying height and focal length. These two parameters are conditioned by technological constraints such as the battery range of the UAV (which affects the duration of the flight, thus the speed of the drone and the rhythm of the photos), and the photographic card memory. It is also important to make sure that the ratio (stereoscopic baseline) / (fly height) is between 1/6 and $1 / 2$ for a better homolog rays intersection (straight lines linking a point on the ground with its corresponding pixels on each picture). A useful formula for the determination of these parameters is:

$$
\frac{f}{H}=\frac{T M}{E}
$$

where

$$
\begin{aligned}
& \mathrm{f}=\text { focal length } \\
& \mathrm{H}=\text { flying height } \\
& \mathrm{T}_{\mathrm{M}}=\text { matrix size } \\
& \mathrm{E}=\text { footprint on the ground of a photograph }
\end{aligned}
$$

\section{AERIAL PHOTOGRAPH ON SITE}

\subsection{Archaeological site of Cempoala}

The archaeological site considered is situated at Cempoala, village of the state of Veracruz (Figure 7). This is a preColumbian ceremonial centre which covers an area of $450 \mathrm{x}$ $250 \mathrm{~m}$. It was the religious centre of a vibrant city at the time of conquest and had to be abandoned due to heavy epidemics that decimated the population. Outside the site itself, many pyramids dot the village and the surrounding fields.

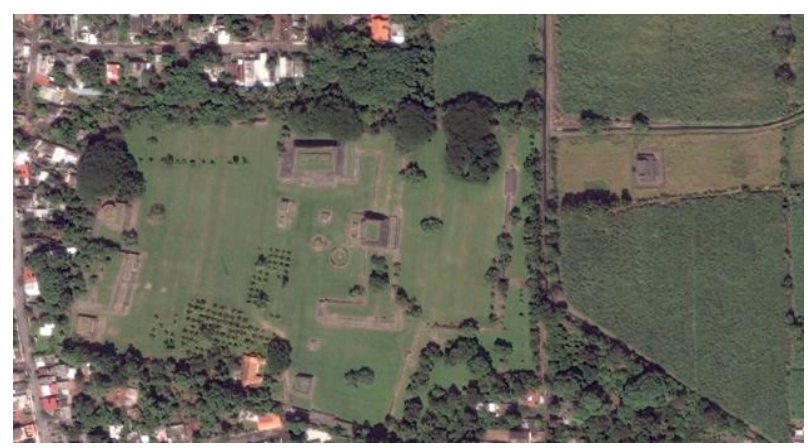

Figure 7. Cempoala archaeological site (Google)
Applied to the archaeological site of Cempoala, these formulas resulted in a flying height of $60 \mathrm{~m}$ above the highest point of the site (the Pyramid of the Sun, approximately $15 \mathrm{~m} \mathrm{high}$ ). The maximal rate of the photographs ( 2.3 seconds) was chosen and a flying speed of $5 \mathrm{~m} / \mathrm{s}$ was calculated. The exposure time used was $1 / 2500$, the ISO 400 and aperture 5.6. The focal length should have been of $28 \mathrm{~mm}$; however, the variable focal length of the objective led it to $26 \mathrm{~mm}$ according to the exif.

The flight plan consists of 13 flight lines (Figure 8). The flight editor announces a flight time of $29 \mathrm{~min}$. The flight plan is divided in 3 flights of respectively 4,4 and 5 bands. Between flights the UAV lands in order to change the battery sets.

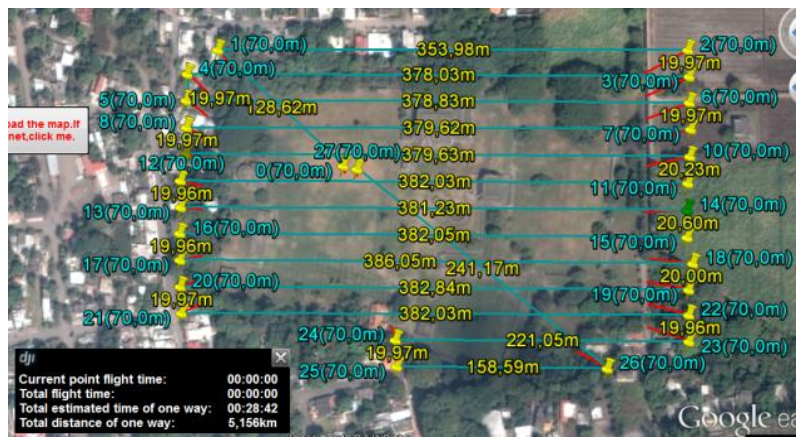

Figure 8. Cempoala flight plan

\subsection{Topographic survey}

Before the flight, seven targets were placed on the ground at the four corners of the site, in the middle of the two long sides and at the centre of the site. They have served as points of control, as they were photographed during flights. The targets are all visible from the top of the central pyramid.

The topographical measurements of control points on the ground are carried out with the total station positioned at the top of the central pyramid of the central site. The total station is a Leica TCR703, allowing an angular accuracy of 1 mgon and 3 $\mathrm{mm}+2 \mathrm{ppm}$ on the distances, according to the manufacturer. Moreover, surveys of the edifices on the site are made using the same total station and a prism.

\section{TREATMENTS}

To obtain orthophotos and 3D models, MicMac software, developed by Marc Pierrot-Deseilligny and the IGN (French National Institute of Geographic and Forestry Information), was used.

We got 364 images that were processed to obtain the aerial photograph (Figure 9).

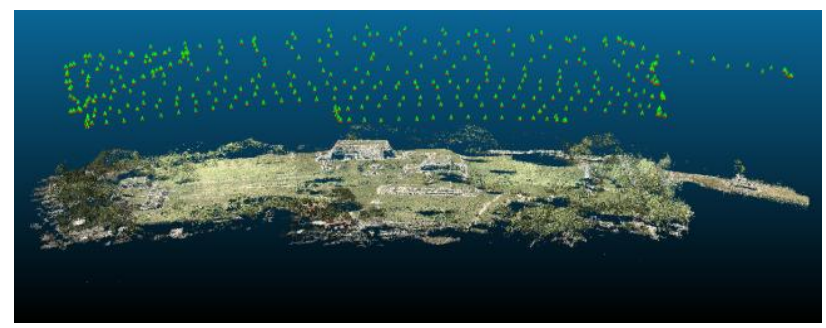


Figure 9. Shot summits

\subsection{Tie points}

MicMac software starts searching the tie points (equivalent points) between the images, before calculating the distortion parameters and thus the calibration of the camera. It turned out that the $3 \mathrm{D}$ point cloud representing the tie points presents a bending which is not in accordance with the reality (Figure 10).

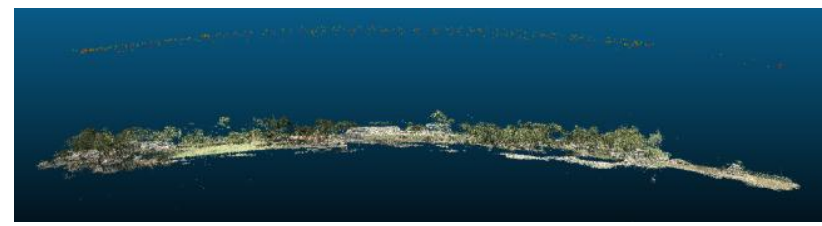

they are not georeferenced and thus remain in a local reference frame. This use of coordinates obtained with the tachymeter unfortunately has very little impact on the bending, as they are in the same plane. The addition of complementary reference points allowed correcting this defect.

\subsection{Orthophoto calculation}

After this, the commands for the creation of orthophotos and 3D models can be launched.

MicMac computes the orthophoto for each individual image, and assembles them to create the orthophoto of the entire site. As the resolution of the final orthophoto is huge, MicMac segments the archaeological site into six pictures, which are assembling manually to give the entire site's orthophoto. (Figure $11)$.

Figure 10. Side view of the point cloud

Thanks to measurements made with the tachymeter on the seven ground control points, the data have been scaled, and oriented roughly as the total station itself has been oriented. However,

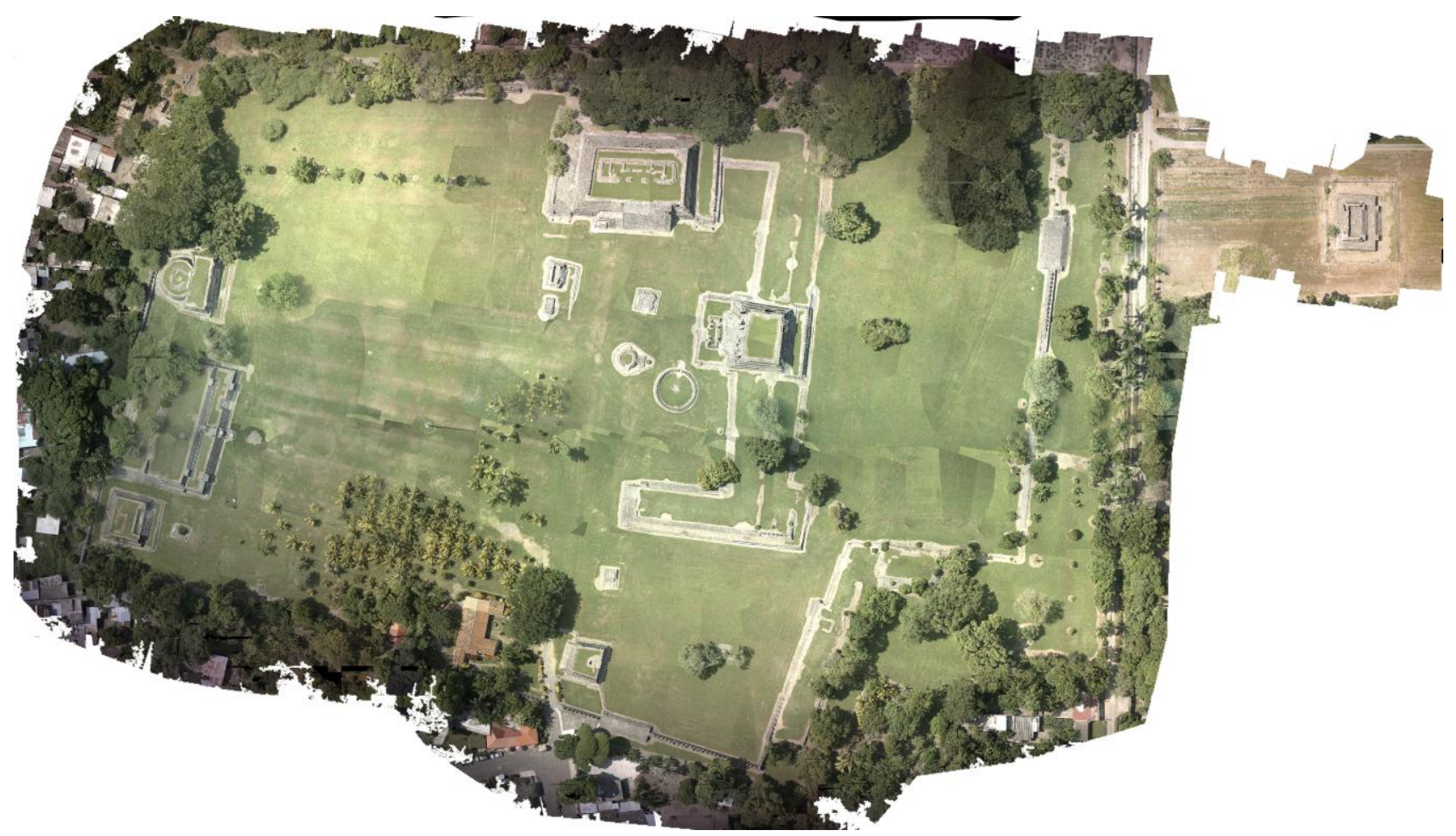

Figure 11. Orthophoto of the archaeological site of Cempoala 


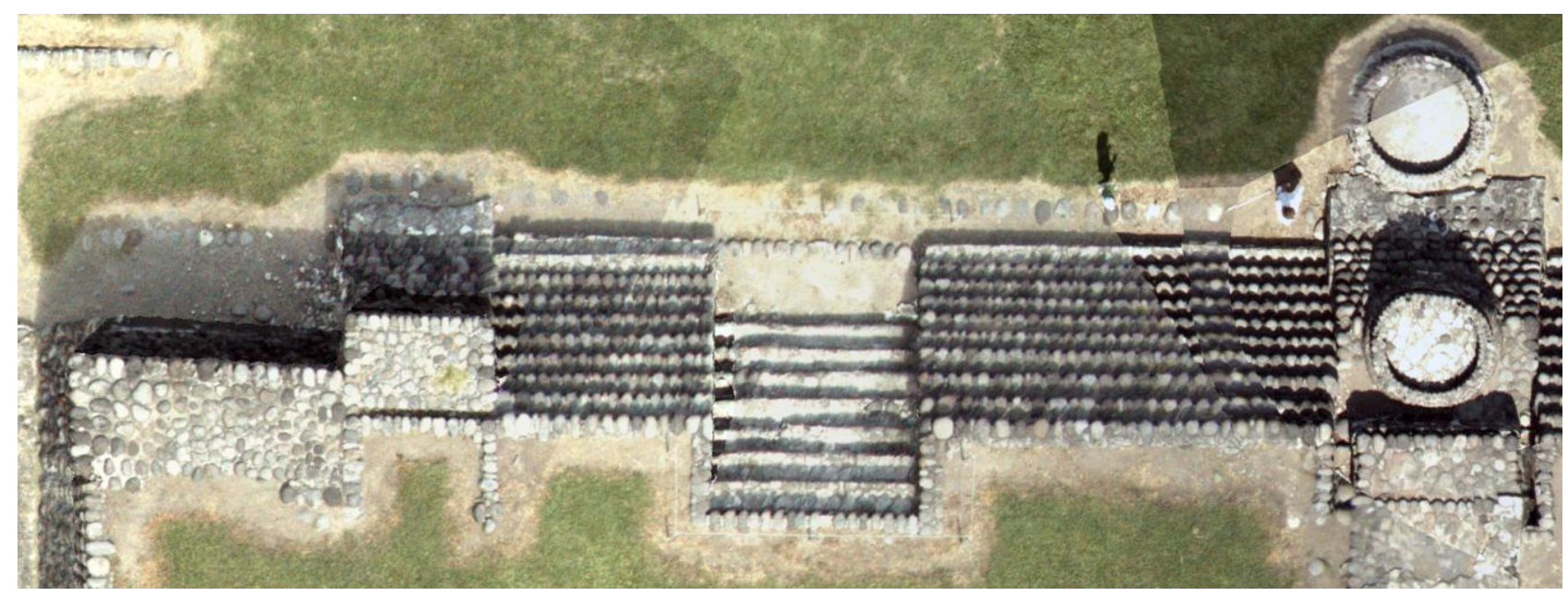

Figure 12. Detail of the orthophoto

The final image presents a darker zone in its central part, which is due to the presence of a few clouds. As each photographic parameter is fixed before the beginning of the flights in order to avoid any optical movement that would imply the calculation of different calibration models, this effect cannot possibly be avoided. The different illuminations observed on the final orthophoto form geometric shapes due to the assembling of individual orthophoto performed by the software to create the overall orthophoto (Figure 12).

\subsection{D model}

The 3D model has a lot of holes mainly where there are trees and in large grassy surfaces (Figure 13). This latter defect could have been avoided with larger footprints of the photos.

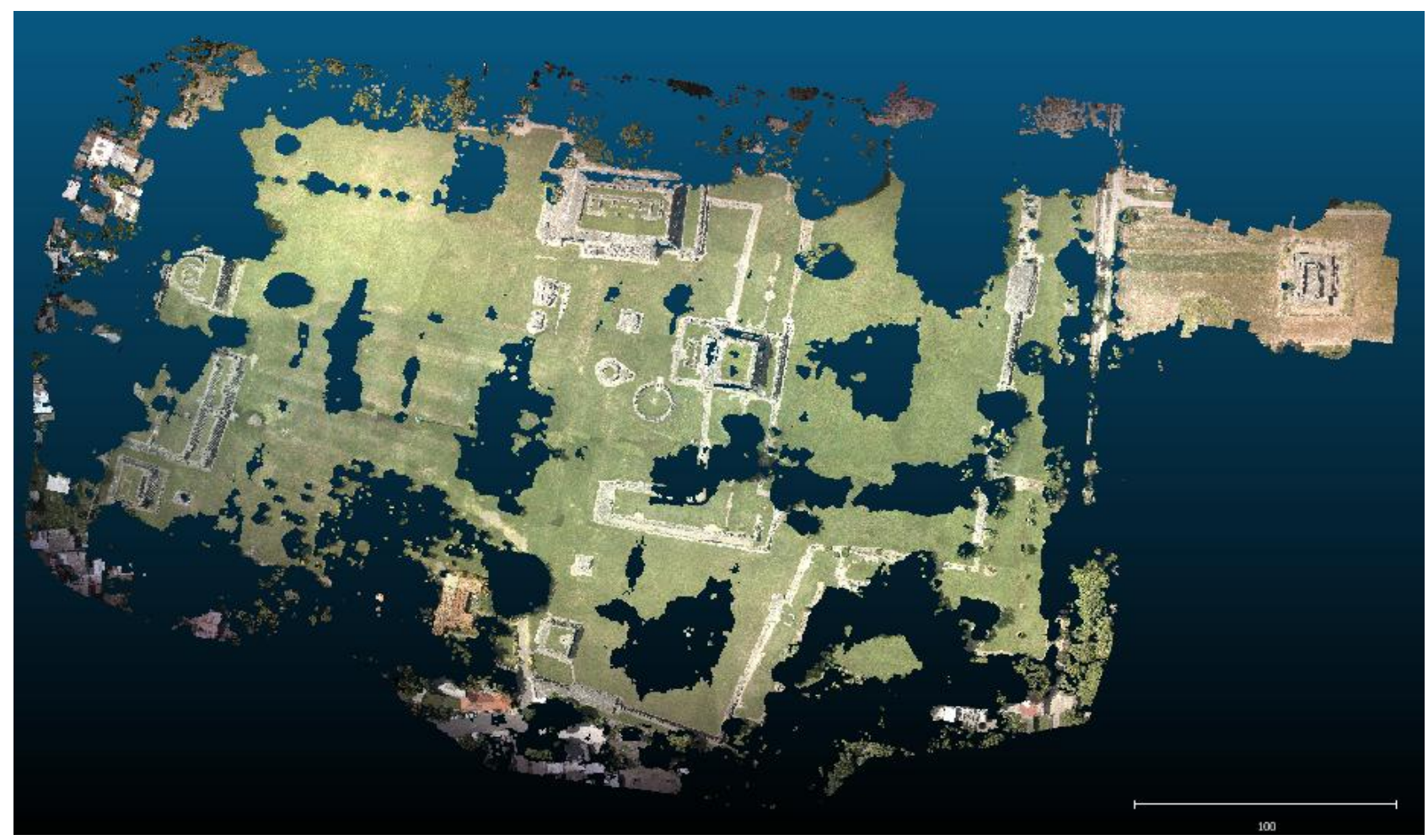

Figure 13. 3D model of the archaeological site of Cempoala, from above

There are also information gaps for vertical surfaces (Figure 14). 


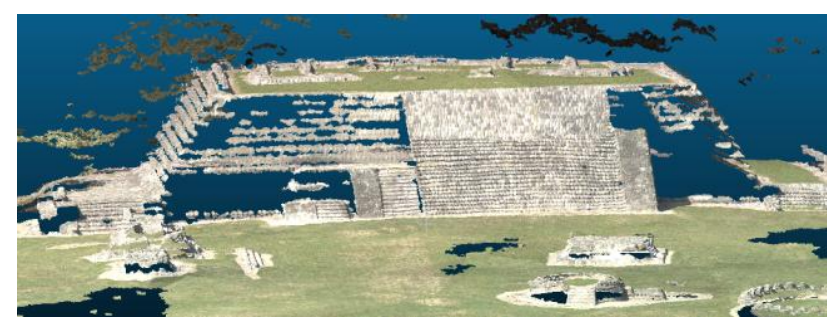

Figure 14. Detail of the 3D model of the archaeological site of Cempoala

This can be due to a too low focal length. Indeed, if the lens angle is low, vertical walls are barely visible in the photographs, and Micmac will consequently struggle to correlate on the walls. Maybe an aerial photograph of the walls with the camera inclined at an angle of $10^{\circ}$ should also be done, which is possible with the mount in possession of the working group.

\subsection{Quality control}

Two factors must be taken into account for centimetric quality control: resolution and accuracy.

The resolution is the size of the ground surface represented by a pixel on the image. The precision corresponds to the positioning error of the pixel.

To obtain these two values, the seven ground control points whose topographic coordinates are known will be used, as well as field points whose coordinates were recorded during the survey made with the total station.

This second data set has the disadvantage of being less accurate because of the ambiguity due to the positioning of the prism which must be imagined on the pictures because at first it was not intended to be used for other purposes than to draw a plan. Nevertheless, this second set of data was not involved in MicMac calculations and conserves greater neutrality.

There are seven ground control points, and six points from the tacheometer survey are selected. For each, cartesian coordinates in the local reference system are calculated from data taken at the total station, and the corresponding image coordinates (in pixels) of the orthophoto are noted, as well as their coordinates in the 3D model. The distances are then calculated and compared.

The average size of the pixel of the orthophoto obtained with the seven ground control points is $1.1 \mathrm{~cm}$. The same value is obtained with the points from the survey. The final orthophoto (3.55 GB) consists of $26868 * 47348$ pixels for a ground footprint of $270 * 500 \mathrm{~m}$, so the pixel size found previously is confirmed $(10.0 * 10.5 \mathrm{~mm})$.

With regard to accuracy, the error on distances is $1.7 \mathrm{~mm} / \mathrm{m}$ if the calculations are carried out with the ground control points and of $5.1 \mathrm{~mm} / \mathrm{m}$ if the calculations are carried out with the survey points. This larger error with the second data set can be due to the greater vagueness of the prism position, and the shorter distances between points.

The same procedure is applied to the 3D model.

The 3D model was obtained with only the seven ground control points and not recalculated after the addition of reference points. The accuracy of the 3D model therefore remains highly flawed vertically. The target number 2, located on the top of the pyramid presents incorrect distances of several dozens of centimeters with other targets.
The error per meter is $5.7 \mathrm{~cm}$ in average, taking into account the seven control points. If measurements on the second target are removed, this error drops to $1.2 \mathrm{~cm} / \mathrm{m}$.

\section{CONCLUSIONS}

Aerial photograph with UAV is a method appreciated for its relatively low cost, handiness, and the amount of information it captures. It provides, through photogrammetry software such as MicMac, satisfactory results with high resolution, but remains dependent on a good calibration to obtain reasonable accuracy (Remondino, 2011).

Its use can be added to total station surveying, it is an ideal solution when the archaeological area is not heavily wooded and when the structures are not protected by a roof, which is the case in many Mexican sites.

It provides a huge amount of information in a very short time and post processing is mainly computer work which does not require as many man-hours of work as traditional solutions.

\section{REFERENCES}

Cabrelles, M., S. Galcerá, S. Navarro, J.L. Lerma, T. Akasheh, and N. Haddad. "Integration of 3D Laser Scanning, Photogrammetry and Thermography to Record Architectural Monuments.” In 22nd CIPA Symposium. Kyoto, Japan, 2009.

CIPA. Photogrammetric capture : the "3* 3 " rules. Sofia, 1988, $1 \mathrm{p}$.

Eisenbeiß, H., 2009. UAV Photogrammetry, doctorate, ETH Zurich, $237 \quad$ p. $\quad$ http://www.igpdata.ethz.ch/berichte/Blaue_Berichte_PDF/105.pdf (03 March 2014)

Ferrieres (de), M., 2004. Notions de photographie, prise de vue photogrammétrique. In: Ferrieres (de), M. Eléments de technologies pour comprendre la photographie : argentique et numérique. Paris : VM éditions, $21 \mathrm{p}$.

Grussenmeyer, P., T. Landes, T. Voegtle, and K. Ringle. "Comparison Methods of Terrestrial Laser Scanning, Photogrammetry and Tacheometry Data for Recording of Cultural Heritage Buildings." The International Archives of the Photogrammetry, Remote Sensing and Spatial Information Sciences XXXVII, no. B5 (2008): 213-218.

Hasegawa, H., Matsuo, K., Koarai, M., Watanabe, N., Masaharu, H., and Fukushima, Y., "DEM Accuracy and the Base to Height $(\mathrm{B} / \mathrm{H})$ Ratio of Stereo Images" International Archives of the Phtotogrammetry, Remote Sensing and Spatial Information Sciences XXXIII, no. B4 (2000): 356-359.

http://www.micmac.ign.fr

Martínez del Pozo, J. Á., Cerrillo- Cuenca, E., and Salas Tovar, E.. "Low Altitude Aerial Photography Applications for Digital Surface Models Creation in Archaeology." Transactions in GIS, 17(2), (2013): 227-246.

Remondino F., Barazzetti L., Nex F., Scaioni M., Sarazzi D., 2011. UAV photogrammetry for mapping and 3D modeling : current status and future perspectives. Zurich, $7 \mathrm{p}$. 
Verhoeven, G., and Docter, R., "The Amphitheatre of Carnuntum - Towards a Complete 3D Model Using Airborne Structure from Motion and Dense Image Matching" 10th International Conference on Archaeological Prospection. Austrian Academy of Sciences, (2013): 438-440.

Verhoeven, G., Sevara, C., Karel, W., Ressl, C., Doneus, M., and Briese C., "Undistorting the Past: New Techniques for Orthorectification of Archaeological Aerial Frame Imagery", Good Practice in Archaeological Diagnostics, Springer International Publishing, (2013): 31-67.

\section{ACKNOWLEDGEMENTS}

I thank Victor Godoy for the control and manipulation of the drone,

Irais Hernandez for the survey with the total station,

Casas Araceli for the processing of the data recorded with the total station.

Finally, I want to thank Marc Pierrot-Deseilligny and the IGN team working on the development of the MicMac software. 